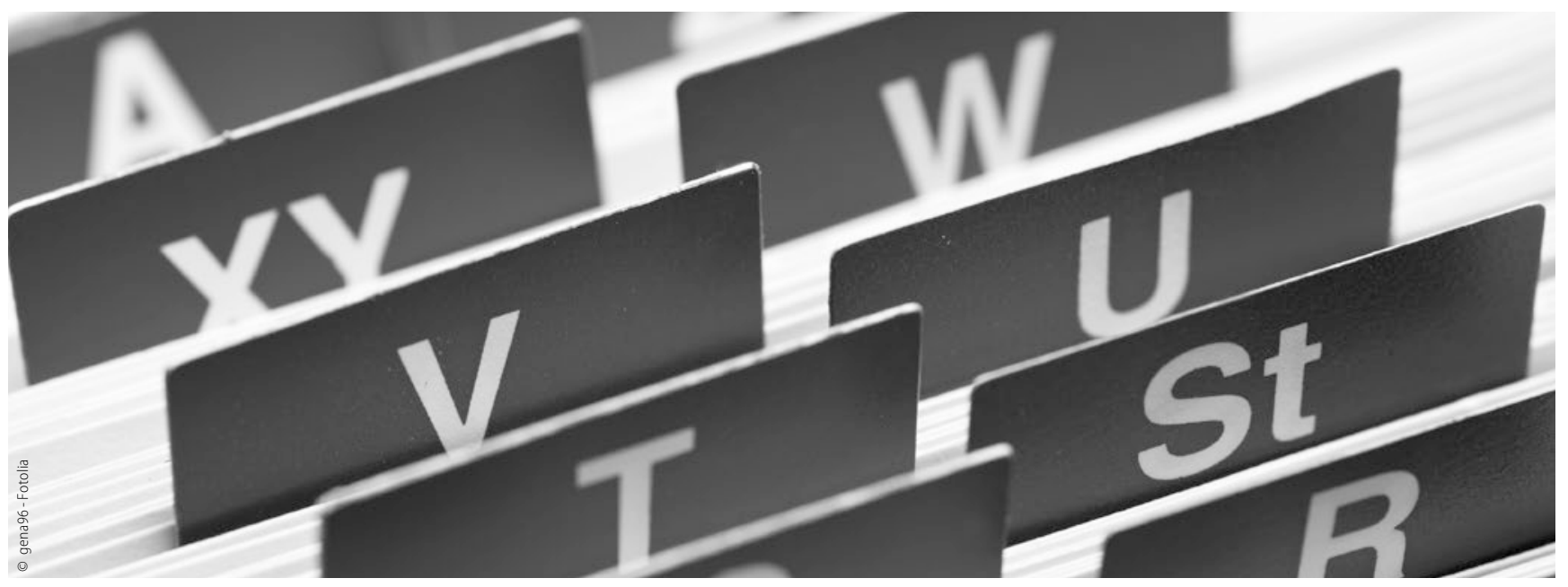

Buchhaltungs- $A B C$

\title{
W wie Wertermittlung - Die Abschreibung
}

Jedes Unternehmen benötigt zur Leistungserbringung Maschinen, Geräte, Betriebseinrichtung und nicht zuletzt Betriebsräume. Diese werden mit Gründung der Unternehmung oder im Laufe des Arbeitsprozesses angeschafft und stellen einen erheblichen Anteil des Unternehmenswertes dar.

Natürlich ist dieser Teil des Unternehmenswertes nicht fix, sondern verändert sich im Laufe der Zeit. In der Regel führt die Benutzung der Güter zu deren Abnutzung, und diese muss auch in Zahlen festgehalten werden, um jederzeit den Wert des Gerätes oder der Einrichtung realistisch darzustellen. $\mathrm{Zu}$ diesem Zweck werden wertmindernde Abschreibungen in der Buchhaltung erfasst. Diese können unterjährig oder am Jahresende gesammelt gebucht werden. Zur unterjährigen Beurteilung des betriebswirtschaftlichen Ergebnisses sollten jedoch zumindest kalkulatorische Abschreibungen angesetzt werden.

\section{Abschreibungen differenziert verbuchen}

Um die Übersichtlichkeit der Abschreibungsbuchungen zu erhöhen, werden differenzierte Konten für die Abschreibung genutzt. Üblich sind diese für Fahrzeuge, Anlagevermögen, geringwertige Wirtschaftsgüter (GWG), immaterielle Wirtschaftsgüter (Praxiswert) und kalkulatorische Abschreibung.

Die Abschreibung der Güter erfolgt bis auf wenige Ausnahmen über mehrere Wirtschaftsjahre. Über welchen Zeitraum ein Gut abzuschreiben ist, kann den von den Finanzbehörden veröffentlichten Abschreibungslisten entnommen werden. Diese gibt es auch branchenspezifisch, also auch für Zahnärzte.

\section{Kalkulatorische Abschreibungen}

Wer seine Jahresverkehrszahlen selbst buchhalterisch erfasst, sollte zumindest kalkulatorische Abschreibungen ansetzen. Diese werden beispielsweise anhand der Abschreibungswerte des Vorjahres festgesetzt und dann monatlich verbucht. Bei großen Neuinvestitionen muss unterjährig der Betrag der kalkulatorischen Abschreibungen angepasst werden. Am Ende des Jahres werden die kalkulatorischen Abschreibungen ausgebucht und die sachlich und rechnerisch aktualisierten Jahresabschreibungen verbucht.

Nächster Tipp: G - Geringwertige Wirtschaftsgüter

\section{Mehr Infos unter www.fibu-doc.de \\ Das in den Artikeln dargestellte Buchhaltungskonzept basiert auf der zahnarztspe- zifischen Buchhaltungssoftware fibu-doc und wird vom FVDZ unterstützt.}

\section{Seminare \\ Personalkosten: Kennen - gestalten - kontrollieren 11.11.2015 - Frankfurt \\ Praxiskennzahlen: Verstehen - vergleichen - verbessern 04.12.2015 - Nürnberg}

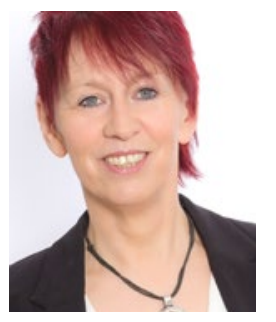

Barbara Mertens

www.fibu-doc.de 